\title{
El camino hacia una medicina más humana
}

\section{The road towards a more humane medicine}

Entre el 25 y 27 del pasado mes de abril se realizó en Buenos Aires el Primer Encuentro Nacional de Humanismo en Medicina organizado por la Sociedad Argentina de Pediatría (SAP). Sin duda que este evento marcó un hito en las actividades académicas de la SAP en su intensa y comprometida misión durante más de 100 años dedicados al cuidado de los niños. En general, los hechos que se definen como un hito responden a múltiples y variados motivos dependientes de cada situación, lo cual hace que las justificaciones para esa denominación no sean fáciles de precisar. A mi juicio, en este caso el hito está representando la creación de un espacio exclusivamente dedicado al humanismo, uno de los dos pilares, junto a la ciencia, que sostienen a la medicina. Ambos son vitales, pero es indudable que si este Encuentro llegó a constituirse fue por la necesidad de retomar un camino que nos lleve a un destino más luminoso, en una época en que la medicina está ganando prestigio por los notables avances científicos y al mismo tiempo lo está perdiendo por su creciente deshumanización.

La idea de organizarlo se basó en la convicción de que algo debíamos y podíamos hacer, ya que si ese desequilibrio entre los dos pilares sigue creciendo y no apuntalamos fuertemente el humanismo, nuestra profesión pierde su sentido de ser y pierde asimismo, los impulsos originales y los principios éticos basados en la solidaridad hacia el prójimo a través del cuidado de la salud y el alivio del sufrimiento.

La experiencia fue sumamente fructífera ya que se pudieron abarcar varios aspectos del humanismo desde diversos puntos de vista y por diferentes actores. Esto fue posible por la convergencia de las Ciencias Sociales y la Medicina en un relevante intercambio de ideas, opiniones y propuestas de profesionales de esas dos disciplinas ante los múltiples problemas que enfrenta actualmente el cuidado de la salud. Entre acuerdos y divergencias, se generó una mirada amplia hacia los aspectos que influyen y participan en la atención de los pacientes y que suelen estar ocultos detrás de las enfermedades o padecimientos. No hubo "recetas" ni recomendaciones definitivas, por el contrario muy probablemente el mayor logro fue el impacto que los temas tratados pudo haber producido dentro de cada uno de los asistentes y el reconocimiento de cuántas debilidades tenemos en nuestra tarea cotidiana que nos alejan de los verdaderos intereses de los pacientes.

Es de señalar un punto, que en cierta forma es representativo del lugar que ocupa el humanismo en la práctica médica actual. El número de inscriptos fue algo inferior a 150, aun cuando el Encuentro contó con amplia difusión, un costo de inscripción muy bajo (cerca de 10 veces menos que otras actividades académicas) y se desarrolló en Buenos Aires, una ciudad con una alta densidad de población. ¿Cuántos asistentes hubieran concurrido si el motivo del Encuentro se relacionaba con una o más enfermedades frecuentes? ¿Cuántos, si se abarcaban temas específicos de tratamientos y de diagnóstico o se presentaba un nuevo medicamento?, sin ninguna duda que muchos más.

Sin embargo, habíamos previsto que esto iba a ocurrir y no nos sorprendió en absoluto, por el contrario nos reafirmó que el Encuentro era necesario y que a través de esos días que compartimos, todos los presentes, en más o en menos, estábamos contribuyendo a generar un punto de partida que con el tiempo pudiera afianzarse y constituyera un espacio que nos ayude a sostener ese insustituible pilar de nuestra profesión que es el humanismo.

Ahora, para poder definir mejor ciertos aspectos, deseo brevemente realizar algunas reflexiones acerca de los factores que a $\mathrm{mi}$ entender influyen con mayor notoriedad en las vicisitudes que atraviesa la medicina y las consecuencias que eso acarrea sobre la profesión médica. Es indudable que en el control y la prevención de muchas enfermedades, aun con falencias e inequidades, se han logrado enormes y notables avances en un breve período de tiempo, digamos en los últimos 50 años, que superan por mucho a los producidos en los miles de años transcurridos desde las primeras civilizaciones.

Sin embargo, aunque parezca paradójico uno de los mayores problemas de la medicina actual es su propio éxito científico. El objetivo o fin de la ciencia médica es estar al servicio de la humanidad y mantenerse siempre por el camino de la beneficencia, es decir hacer el bien, pero, por diversos motivos, ocurrieron y siguen ocurriendo cada vez más, ciertos desvíos de ese principio básico que obviamente son perjudiciales. Esos 
desvíos se deben principalmente a factores externos, sería extenso señalar a todos, que se "introdujeron" en la medicina y que sin duda influyeron para que los avances trajeran aparejadas consecuencias no tan auspiciosas, tanto para la población en general como para los médicos. En este proceso del avance arrollador de la ciencia y la tecnología, parece que no es sencillo diferenciar lo bueno de lo malo y seguir en todo momento el rumbo correcto. El éxito puede encandilar a muchos y generar el convencimiento que lo más importante, o casi lo único importante en la medicina es el conocimiento científico y de esa forma se van perdiendo los otros principios esenciales de nuestra profesión basados en la relación humana con los pacientes y en cuidar solo sus intereses.

El filósofo alemán Hans Jonas, en sus magníficos ensayos acerca de las falencias éticas de la medicina contemporánea, destacó entre sus causas el aparente éxito que tuvieron el apabullante progreso científico asociado a la "invasión" tecnológica y su inadecuado uso. Asimismo, destacó que es necesario tomar conciencia de tener el mayor cuidado y precaución cuando la eficacia de un presunto avance o de una nueva tecnología, presenta beneficios inmediatos. Los problemas futuros están más asociados al éxito que al fracaso, por lo cual es imprescindible que siempre se evalúen correctamente los riesgos potenciales, ya que los daños pueden ser irreparables. Debemos temer más a nuestro poder que a nuestra impotencia y frente a la incertidumbre actuar en todo momento con cautela y humildad.

Estos aspectos señalados y otros más produjeron enormes cambios en la medicina, que pasó de ser una disciplina "mal vista" por la gente hasta mediados del siglo 19 , momento en el cual los médicos comenzaron a tomar conciencia de que sabían muy poco y que los tratamientos que indicaban eran mucho más perjudiciales que beneficiosos. Eso trajo aparejado el desarrollo de una medicina más humana al comprender que el acompañamiento de los pacientes con la ayuda y el consuelo en sus pesares era lo más importante. Los médicos fueron ganando respetabilidad y lograron obtener la confianza de la gente, elemento imprescindible en toda relación humana, alcanzando un gran reconocimiento en la sociedad. Así renacieron los principios ancestrales de nuestra profesión, algo que quedó excelentemente retratado por el filósofo francés Michel Foucault, que en su libro El Nacimiento de la Clínica, nos dice: "Lo que era fundamentalmente invisible se ofrece de repente a la claridad de la mirada... Se tiene la impresión de que, por primera vez desde hace milenios, los médicos, libres al fin de teorías y quimeras, han consentido en abordar para ellos mismos y en la pureza de una mirada, el objeto de su experiencia".

Es indudable que ese impulso fue mermando notablemente en especial luego de la segunda guerra mundial, cuando todo cambió y el mundo no volvió a ser igual. Debemos aceptar que los cambios son inexorables y continuarán con mayor o menor intensidad en la vida de los seres humanos. No obstante, nosotros, los médicos tenemos que preguntarnos por qué esos cambios pueden ensombrecer o relegar las metas esenciales de la medicina que no se basan solo en los aspectos científicos sino también en mantener otros principios sin los cuales perderíamos nuestra mayor virtud.

Deseo aclarar, para evitar malos entendidos, que sin duda los aspectos científicos son esenciales, los pacientes quieren que nosotros seamos aptos y tengamos los suficientes conocimientos y el adecuado juicio clínico para saber qué les sucede, pero asimismo, quieren que los escuchemos, que conozcamos sus dudas y temores, que los ayudemos cuando su salud se afecta, que los acompañemos, en fin, que estemos a su lado. Esto último no se aprende en los libros, pero sí se puede cultivar y de esa forma aplicarlo en la práctica cotidiana. Gianantonio, nuestro siempre presente maestro, nos decía que todo acto médico, aun el más sencillo, lleva implícito una actitud ética que es absolutamente inseparable del conocimiento científico.

Estos aspectos que he señalado nos muestran que el camino hacia una medicina más humana solo puede construirse por lo que cada uno de nosotros pueda realizar para alcanzar ese fin. No esperemos que otros lo hagan ni que haya modificaciones sustanciales en la profesión médica que mejoren su situación. Los pacientes siempre van a desear de nosotros una actitud empática y el compromiso de ayudar; es nuestro deber no defraudarlos.

José M. Ceriani Cernadas Editor

http:/ /dx.doi.org/10.5546/aap.2013.274 